\title{
Food and Sustainability: A New Paradigm in Spanish Food Based Dietary Guidelines
}

\section{Javier Aranceta*}

Department of Preventive Medicine and Public Health, University of Navarra

"Corresponding author: Javier Aranceta, Spanish Society of Community Nutrition (SENC), Department of Preventive Medicine and Public Health, University of Navarra; E-mail: javieraranceta@gmail.com

\begin{abstract}
At present, food supply and sustainability are an indivisible binomial that aims to create a trail of health and sustainability in all directions. The new Dietary Guidelines for the Spanish population developed by the Spanish Society of Community Nutrition (SENC) provide specific recommendations compatible with better health. Include explicit and implicit recommendations towards priority food consumption that contributes to reduce ecological foot print and promote sustainability in terms of food, economy and social development.
\end{abstract}

Keywords: Food-Based Dietary Guidelines; Sustainability; Mediterranean diet
Received date: September 07, 2016

Accepted date: November 29, 2016

Published date: December 04, 2016

Citation: Aranceta, J. Food and Sustainability: A New Paradigm in Spanish Food Based Dietary Guidelines. (2016) J Environ Health Sci 2(4): 1- 3.

DOI: $10.15436 / 2378-6841.16 .1097$

\section{Introduction}

Community Nutrition deals with improving the availability and facilitating access to communities to a variety of resources that contribute to the adoption of food habits and lifestyles of individuals and population groups consistent with health promotion and quality of life of present and future generations.

Climate change and environmental concerns in recent years have led the scientific community to focus its attention on the health of the planet as a primary endpoint for all activities, including food related processes, from initial seed development, cattle breeding or marine fish captures, until its classification as waste or residues: raw materials containers, packaging and processes involved (Burlingame, B., et al., 2010).

All human activities have a clear impact on the socalled ecological footprint. Food affects the use of land, water consumption, energy consumption, $\mathrm{CO}_{2}$ generation, waste impact, environmental pollution and often, labor and social injustice (Auestad, N., et al., 2015).

Since the beginning of this new century concerns about the environmental impact of food has been increasing in all areas of society. At present food supply and sustainability are an indivisible binomial that aims to create a trail of health and sustainability in all directions (Johnston, J.L., et al., 2014).

\section{Sustainable diets}

Experts agreed on a general definition in the context of an FAO meeting on biodiversity and sustainable diets in Rome in 2010 and subsequent report: "Sustainable diets are those diets with low environmental impacts which contribute to food and nutrition security and to healthy life for present and future generations. Sustainable diets are protective and respectful of biodiversity and ecosystems, culturally acceptable, accessible, economically fair and affordable; nutritionally adequate, safe and healthy; while optimizing natural and human resources" (Burlingame, B., et al., 2010). Despite the increasing visibility of these issues, just a few sets of food-based dietary guidelines (FBDG) have considered sustainability criteria in their approaches. As pointed out in a recent analysis on sustainability in FBDG, so far, only four countries consider sustainability in official FBDG, namely Brazil, Sweden, Qatar and Germany. A few others, such as USA and Australia, provide some discussion on sustainability issues in additional reports, although such considerations did not achieved formal endorsement. In addition, recent documents developed in a number of countries, such as UK, France, the 
Netherlands and Estonia include sustainability (Gonzalez, et al., 2016).

\section{Dietary Guidelines: Health criteria}

The new FBDG for the Spanish population developed by the Spanish Society of Community Nutrition (SENC) include specific recommendations on various determinants of nutritional status and eating habits compatible with better health (figure 1). Through the icon of the Healthy Eating Food Guide Pyramid, recommendations on daily physical activity ( 1 hour or 10,000 steps), highlights about emotional balance, energy balance, culinary techniques and intake of water and other liquids form the base of the picture.

On these premises, dietary recommendations focus on an important position for whole grain cereals, tender legumes, fruit and vegetables. In this block of foods for priority consumption, the use of extra virgin olive oil is emphasized both for seasoning raw foods and for cooking, frying and other culinary techniques.

In the upper levels of the pyramid a variety of foods to choose are included as recommended for daily or weekly consumption we find low-fat dairy products, nuts, dry beans, eggs, white meats and seasonal fish.

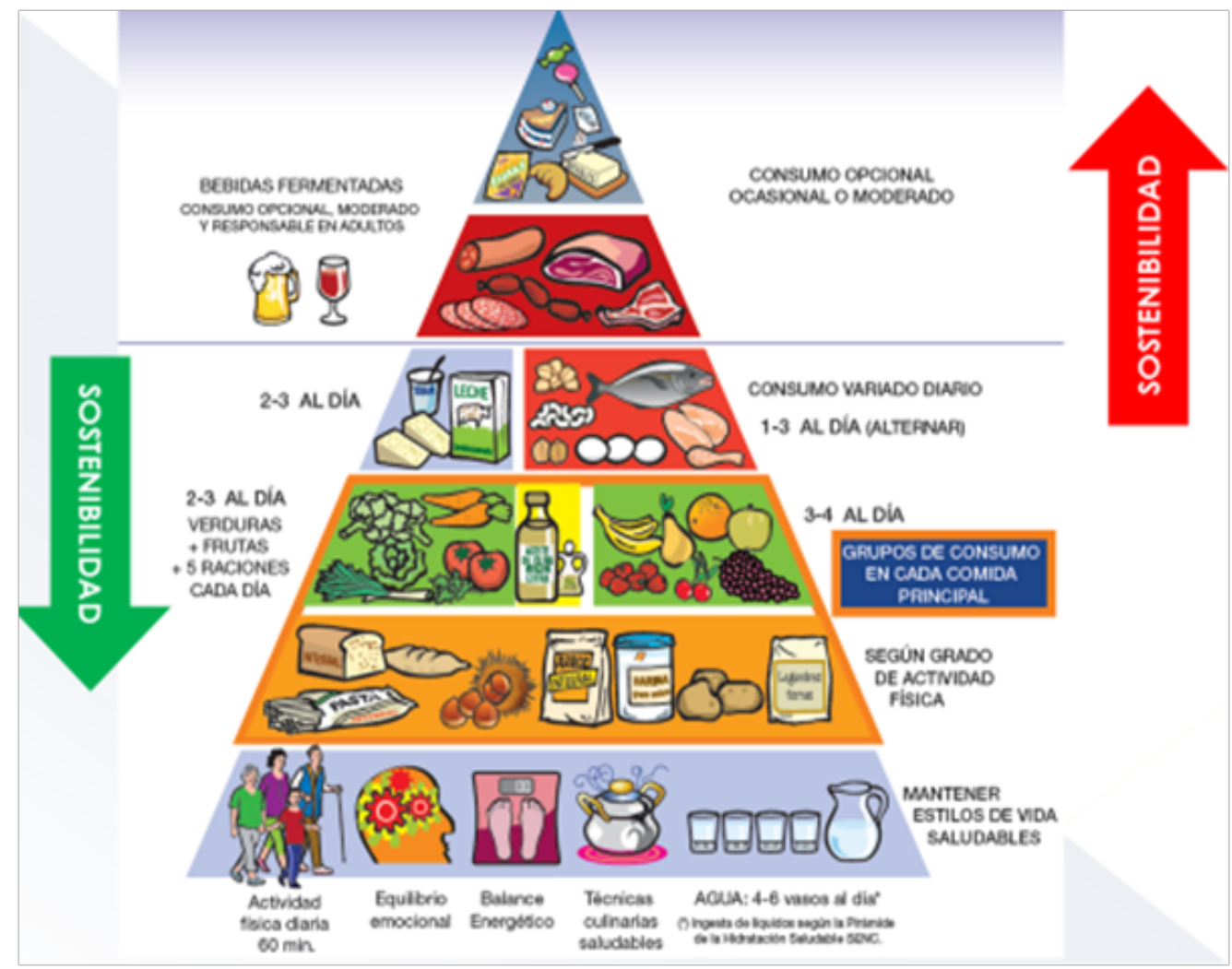

In the fourth level, we can see foods recommended for occasional consumption, such as red meat, sausages and other processed meats. This recommendation is completed with additional advice to choose good quality eat and meat products, with side dish of salad or fresh vegetables and using cooking techniques that prevent adding unwanted byproducts.

At the apex of the pyramid fat spreads, foods high in sugar, salt and sweets, snacks and goodies are positioned.

In this new edition, the icon reminds individuals to ask for professional health advice if willing to incorporate dietary and/or nutritional supplements, vitamins or certain functional foods based on individual characteristics.

\section{Sustainability criteria}

Explicit and implicit recommendations are also directed towards priority food consumption that generates reduce ecological footprint and promote sustainability in terms of food, economic and social terms. The base of plant foods adds indications to choose products in season, local or proximity products, and reminds about demanding products obtained by processes respectful with the environment. These additional advices include as well, criteria of food sovereignty and consider fair trade and ethics of food on all fronts.

Although consensus for the guidelines agreed considering elements of comfort and respect for common customs and uses, health and sustainability criteria advice to decrease consumption of animal-origin food products and increase consumption of vegetables, fruits and legumes.

Regarding the ecological footprint, Spain exceeds 2.5 times the overall impact from food, housing, transportation, etc. It also describes figures for improvement in relation to waste reduction, safe reuse and suitable recycling of food and packaging.

In this sense, the food groups with poorest balance and greater impact on the $\mathrm{CO}_{2}$ footprint refers to meat, some manufactured fish, dairy products and processed foods high in salt and/or sugar.

\section{Live Well for Life project estimates for Spain}

The Life Well for Life project, developed by WWF (World Wildlife Fund) and Friends of Europe- seek to promote the adoption of healthier and more sustainable European eating habits (Thompson, S., et al., 2016). Among other, aims to suggest changes in eating patterns of pilot European countries, namely France, Sweden, and Spain, with the aim of reducing by $25 \%$ the greenhouse gas emissions in a feasible way by intro- 
ducing small changes. According to Live Well for Life project estimates for Spain, in the case of meat and meat products, the goal would reduce the consumption from $139 \mathrm{~g} / \mathrm{pc} /$ day to only $100 \mathrm{~g}$. The target for sugar would reduce from $15 \mathrm{~g} / \mathrm{pc} /$ day to 10 g. The suggestion for vegetables would increase consumption from $183 \mathrm{~g}$ to $300 \mathrm{~g} / \mathrm{pc} /$ day; fruits of a current consumption of $209 \mathrm{~g}$ to $300 \mathrm{~g}$ and legumes from $28 \mathrm{~g}$ to $40 \mathrm{~g}$. These changes are consistent with the recommendations raised in the SENC-FBDG and are a possible target in the medium term.

\section{Guidelines for action}

The guidelines for action are very close to the holistic characteristics of the Mediterranean Diet, declared Intangible Heritage of Humanity, which promotes harmony between the surrounding nature, people and cuisine. A lifestyle, a philosophy, which promotes conviviality, the characteristic landscapes of cereal crops, vineyards and colorful fruit orchards.

Gastronomy and health together by the ancient wisdom of families and people under Mediterranean influence, although they maybe also influenced by the Cantabrian Sea and even the Atlantic (as the Canary Islands or Portugal).

Some practical considerations that were raised at the Expert Meeting SENC-2016 held in the Canary Islands under the coordination of Dr. Ll. Serra Majem:

1. Prioritize the consumption of plant foods

2. Reduce consumption of meat and meat products

3. Eat fish and seafood compatible with sustainable fisheries cycles (species and capture system)

4. Prioritize food choices and products according to their impact on the ecological footprint

5. Reduce consumption of foods high in fat, salt and added sugars

6. Reduce waste, reuse and recycle safely all leftover items

7. Prioritize food with quality seals in relation to sustainable food

8. Choose seasonal produce, local or nearby, building a varied and enjoyable diet.

We are convinced that the implementation of these recommendations is an urgent and necessary task for our better survival. Promotion actions should begin by public authorities and administrations with the involvement of the health and education sector. There is a great awareness of this issue in all Regions of Spain. The best proof is in the results of recycling (plastic, glass, cardboard, organic material, cooking oil, electronic equipment, used clothing, batteries) and so on. Even some regions in the North of the country are located at the head of Europe in this good practice. The catering sector must play a prominent role as well, but perhaps the key factor is the ability of consumer to choose towards products, food and more sustainable forms of life.

\section{Reference}

1. Burlingame, B., Dernini, S., FAO. Sustainable diets and biodiversity: Directions and solutions For policy, research and action. (2010) Proc Intl Sci Symposium.

2. Auestad, N., Fulgoni, V.L., $3^{\text {rd }}$. What Current Literature Tells Us about Sustainable Diets: Emerging Research Linking Dietary Patterns, Environmental Sustainability, and economics. (2015) Adv Nutr 6(1): $19-36$.

3. Johnston, J.L., Fanzo, J.C., Cogill, B. Understanding Sustainable Diets: A Descriptive Analysis of the Determinants and Processes That Influence Diets and Their Impact on Health, Food Security, and Environmental Sustainability. (2014) Adv Nutr 5(4): 418-429.

4. Gonzalez, F.C., Garnett, T. Plates, pyramids, planet. Developments in national healthy and sustainable dietary guidelines: a state of play assessment. (2016) FAO.

5. Thompson, S., Gower, R., Darmon, N., et al. A balance of healthy and sustainable food choices for France, Spain and Sweden: Report. (2016) Healthy people, Healthy planet, LifeWell for Life.
Ommega Online Publishers

Journal Title: Journal of Environment and Health Science (JEHS)

Journal Short Name: J Environ Health Sci
Journal ISSN: 2378-6841

E-mail: environmentalscience@ommegaonline.org

Website: www.ommegaonline.org 